\title{
VIOLÊNCIA DOMÉSTICA CONTRA CRIANÇA E ADOLESCENTE: EXPERIÊNCIA DO AMBULATÓRIO DE PEDIATRIA DO HC/UNICAMP
}

\author{
Mirian Franzoloso Santos Martins ${ }^{1}$ \\ Dinalva Cristina Ximenes ${ }^{2}$ \\ Denise Barbieri Marmo ${ }^{3}$ \\ Flávia Pozzolini Faria ${ }^{4}$
}

\section{RESUMO}

Este trabalho aborda aspectos da violência doméstica a partir das relações sociais que ocorrem na vida cotidiana e sua construção na história. Descreve a população atendida no ambulatório de VCCA (Violência contra a Criança e o Adolescente) no Hospital de Clínicas da UNICAMP nos aspectos relacionados à criança o adolescente e sua família. O artigo aponta para a importância do vínculo entre a equipe de trabalho e a família, para a necessidade de ações preventivas, para a sensibilização da sociedade e para o diálogo sobre a questão baseados nos direitos humanos e de cidadania.

PALAVRAS-CHAVE: Violência Doméstica; Criança e Adolescente; Família; Relações Sociais.

(...) Cosette parecia entristecida; apesar de ter somente oito anos, ela já tinha sofrido tanto que ela parecia ruminar com ares de velha. Tinha uma pálpebra machucada por um soco da senhora Thenardier, que dizia: "Que feia ela fica com aquele olho roxo."

(...) A enorme senhora Thenardier - porque assim era chamada uma fêmea daquela espécie - alta, loura, avermelhada, gorda, musculosa, enorme e ágil, daquela raça de mulheres selvagens (...) fazia tudo na casa, arrumava as camas, os quartos, lavava, cozinhava e em geral fazia o que bem queria. Cosette era sua única criada - um camundongo a serviço de um gigante.. Tudo tremia ao som de sua voz, janelas, móveis e pessoas.(...) ela se gabava de quebrar nozes com as mãos. (...) Falava como um policial, bebia como um carroceiro e tratava Cosette como um carrasco ${ }^{5}$.

\footnotetext{
${ }^{1}$ Assistente Social do Serviço Social - HC/UNICAMP e mestranda em Saúde da Criança - FCM UNICAMP.

${ }^{2}$ Assistente Social do Serviço Social - Hospital de Clínicas da UNICAMP.

${ }^{3}$ Professora Doutora do Departamento de Pediatria - FCM UNICAMP.

${ }^{4}$ Psicóloga - aluna de especialização em Psicoterapia de Criança - Departamento de Psiquiatria e Psicologia Médica - FCM UNICAMP.

${ }^{5}$ Trecho da obra de Victor Hugo "Les Miserables", escrita em 1862.

\begin{tabular}{lllll}
\hline Serviço Social \& Saúde & Campinas & v. 3 & n. 3 & p. 1-94 Maio 2004
\end{tabular}
}




\section{INTRODUÇÃO E REVISÃO DA LITERATURA}

A violência contra crianças e adolescentes é tão antiga quanto a história conhecida. Infanticídio era aceito como prática de seleção em culturas pré históricas em face da limitação de recursos.

Darwin postulou que poderia-se correlacionar o início da civilização humana com o infanticídio. - Nossos ancestrais semi-humanos não praticariam infanticídio... pois os instintos dos animais inferiores não são tão pervertidos para regularmente destruir seus filhotes (HEINS, 1984).

Na bíblia os rituais de sacrifícios de crianças eram comuns como nos casos de Isaac e Moisés. Na tradição judia/cristã, acredita-se que a circuncisão e o batismo são símbolos que substituíram o infanticídio, pois somente após a realização destes rituais as crianças recebem o seu nome e sobrenome que permitirá a união da criança à família protetora que lhe deu a vida. As antigas leis romanas dava ao pai o direito absoluto sobre a vida ou a morte da criança. Durante o século quatro a igreja cristã começou a contestar o infanticídio e as leis romanas modificaram. Estas leis foram o início da noção de pátrio poder, que define o direito do estado de intervir na família em defesa da criança. No entanto infanticídio, especialmente de crianças ilegítimas continuaram até recentemente. Abandono em lugar de assassinato declarado foi o método mais usado.

A reforma protestante trouxe o conceito de que as crianças deveriam ser educadas com disciplina o que possibilitaria a criação de uma sociedade mais próxima de Deus na terra. A disciplina passou a ser um dever sagrado das famílias. Os puritanos até estabeleceram a pena de morte para crianças desobedientes, apesar de não existir documentação do seu uso. A doutrina calvinista ditava que as crianças deveriam ser espancadas regularmente para expulsar a sua selvageria inata. Até o século dezessete, o castigo físico era comum. O século dezoito trouxe novas luzes na educação das crianças. Locke e Rousseau acreditavam que crianças aprendiam pela experiência e portanto inocentes perante a sociedade corrupta. A punição corporal não era mais necessária para assegurar a salvação.

\begin{tabular}{lllll}
\hline Serviço Social \& Saúde & Campinas & v. 3 & n. 3 & p. 1-94 Maio 2004 \\
\hline
\end{tabular} 
Durante o século dezenove, crianças pobres foram forçadas a trabalhar muito cedo. Crianças com oito anos trabalhando até dezesseis horas por dia em locais insalubres e mal alimentadas era comum. Na Inglaterra um membro da Câmara dos Comuns caracterizou as oficinas de trabalho como o maior escoamento da mortalidade infantil (MARTOREL, 1981).

No Brasil colônia a idéia do castigo físico foi introduzida pelos jesuítas. Os índios abandonavam a escola porque eram punidos com o tronco e palmatória quando faltavam as aulas. Freyre (1964), em sua obra "Casa Grande e Senzala”, citava casos de crianças que eram castigadas com vara de marmelo, palmatória, cipó, com o objetivo de ensinar obediência aos pais. As crianças escravas eram vítimas de açoites, chicotes e instrumentos de suplício ou sevícias sexuais, por parte de adultos. Serviam para brincadeiras brutais dos filhos dos senhores brancos, que desde pequenos tornavam-se objetos sobre o qual exerciam seus caprichos:

Nas recordações de sua infância o Visconde de Taunay, que foi um homem tão suave, quase uma moça, confessa que gostava de fazer suas judiariazinhas com os muleques (FREYRE, 1964).

O primeiro caso de abuso físico denunciado nos Estados Unidos ocorreu em 1874. Mary Ellen, aos oito anos era espancada e privada de alimento por seus pais adotivos. Mary Ellen, foi retirada de sua casa e colocada em um orfanato e a mãe adotiva foi considerada culpada de espancamento e sentenciada a um ano de prisão. (HEINS, 1984)

O primeiro artigo médico científico que se tem notícia, foi realizado por Ambrose Tardieu, presidente da Academia de Medicina de Paris que publicou em 1860 o trabalho: "Étude médico-legale sur le sevices et mauvais traitments exercés sur des enfants". Ele apresentou 32 casos (18 mortos) de crianças submetidas a sevícias, metade das quais com idade inferior a cinco anos. Descrevia as lesões sofridas (fraturas diversas, queimaduras, hematomas, etc.) e aborda a discordância entre as explicações fornecidas pelos agressores e as características das lesões. Ele faz alusão ao tratamento brutal que crianças sofrem de pais e professores que exercem autoridade mais ou menos direta sobre elas. Descreve algumas características dos pais agressores associadas ao desemprego e isolamento social (GUERRA, 1998). Esta mesma autora comenta que na França do século dezenove, a

\begin{tabular}{lllll}
\hline Serviço Social \& Saúde & Campinas & v. 3 & n. 3 & p. 1-94 Maio 2004
\end{tabular} 
preocupação maior da sociedade era com o parricídio. Estes casos tomavam a imprensa local e eram cantados em versos. Os assassinatos de pais por filhos eram relativamente numerosos nos tribunais. O código francês punia com amputação da mão direita os assassinos de seus próprios pais. A autora cita Foucault que alerta que naquele século, a Revolução foi substituída por uma sociedade menos igualitária, baseada na hierarquia de autoridade e obediência.

A violência física doméstica contra crianças foi retomada e descrita cientificamente somente no ano de 1962, quando H. Kempe e F. Silverman da Universidade do Colorado, Estados Unidos, apresentaram 749 casos (com 78 mortes) e descreveram a "síndrome da criança espancada". Neste artigo os autores registram a freqüência maior da síndrome nas crianças na faixa de menos de três anos, bem como o aparecimento de seqüelas provenientes de hematomas subdurais. Eles haviam observado crianças que eram saudáveis até os sete meses e então desenvolviam "hematoma subdural espontâneo", "ferimentos múltiplos de etiologia desconhecida" ou, "impetigo" cujas lesões mostravam claramente queimaduras por cigarro. A preocupação com estes fatos motivaram uma pesquisa realizada em 71 hospitais e 77 promotores distritais em 1956. Dr. Kempe cita:

Eu sempre tive antipatia visceral por declarações desleixadas em diagnóstico e tratamento, e não pude permanecer alheio a esta forma de cobertura baseada na maioria das vezes em negação ou medo (HEINS,1984).

O artigo foi publicado na JAMA (Journal of American Medical Association) e tornou-se marco fundamental tanto para o público como para a população médica, tendo impacto nacional e internacional. As conseqüências para a sociedade americana vieram na mudança da legislação em 1974 com o "Federal Child Abuse Prevention and Treatment Act”, que estabelecia um centro nacional em Washington, DC, com fundos para pesquisa e projetos no campo de abuso e negligencia infantil. A “International Society for the Prevention of Child Abuse and Neglect” foi estabelecida em 1976.

Analisando sucintamente a situação brasileira das ultimas décadas, observamos que durante os momentos de maior repressão do governo militar, valorizava-se muito a família como esteio da nossa sociedade portanto não interessava num governo autoritário rever 
práticas de educação doméstica. No atual código penal brasileiro, que data da década de quarenta, são passíveis de punição apenas os castigos chamados de imoderados. O código de menores de 1979, não dispensava tratamento diferenciado às vítimas de violência doméstica e tratava como "situação irregular" tanto os casos de vítimas de maus tratos como os de vítimas de negligência. O Estatuto da Criança e do Adolescente, em 1990, modifica a situação, trazendo a notificação obrigatória deste tipo de violência propondo medidas de intervenção em relação à família agressora, protegendo a vítima e salientando também a necessidade de prevenção.

\section{A FAMÍLIA, A CRIANÇA E A VIOLÊNCIA}

"Spare the rod and spoil the child"6

As relações sociais ocorrem na esfera da vida cotidiana das pessoas. Vida que se centra no imediato, mas que foi construída na história. Na verdade, as relações sociais são substâncias da história, como a história é substância da sociedade. Heller (1987), fala que o cotidiano é entendido como uma esfera muito particular da história, na medida em que configura o espaço onde se dão as relações sociais, o espaço onde se desenrola a existência humana.

Em tal espaço, a família ganha um papel muito importante pois é uma comunidade fundamental para o existir humano, para a objetivação do ser, e para a reprodução normal da vida.

Soifer (1982), define a família como o organismo no qual nasce, cresce, evolui, amadurece e morre o ser humano, constituindo-se a base indispensável para todas as pessoas cujo objetivo primordial é a defesa da vida.

A família compõem-se como o primeiro grupo social do ser humano, e a única forma de comunidade real, contrapondo-se ao mundo externo. Dentro da família cada membro deseja receber atenção, respeito e o reconhecimento da própria personalidade.

\footnotetext{
6 "Economize na vara e terá uma criança mimada" - dito popular.
}

\begin{tabular}{lllll}
\hline Serviço Social \& Saúde & Campinas & v. 3 & n. 3 & p. 1-94 Maio 2004
\end{tabular}


O termo "casa” não significa apenas o local de moradia, a cidade, ou o país de nascimento, ela é muito mais do que isto: é sinônimo de família. Assim a família torna-se a esfera íntima da existência, o local exclusivo onde se pode exprimir a própria emoção e agregar-se aos outros. O local onde se pode relaxar em conjunto, o local enfim onde se pode desfrutar a sensação de pertencer. Representa também, o lugar onde se pode refazerse das humilhações sofridas no mundo externo, expandir a agressividade reprimida, exercitar o próprio autocontrole, repreender e vencer o outro (HELLER, 1987).

A separação entre o Estado e a sociedade civil, as relações de mercado e industrialização modificaram lenta, mas radicalmente, o status social da família. A sociedade civil assegura à esfera privada uma relativa independência em relação à esfera pública. Minuchin (1982), comenta que a família tem passado por mudanças que correspondem às mudanças na sociedade. A moderna civilização industrial urbana impõe ao homem duas exigências conflitantes: a capacidade de desenvolver habilidades altamente especializadas e a capacidade de adaptação rápida a uma situação sócio-econômica constantemente em mudança. Também tem assumido ou renunciado a funções de proteção e socialização de seus membros em resposta a dois diferentes objetivos: o interno que se objetiva na proteção psicossocial de seus membros e o externo que se constitui na acomodação a uma cultura e à transmissão dessa cultura. Esta intromissão tem retirado da família funções que eram consideradas deveres familiares. Exemplo desta nova situação é o apoio econômico fornecido pela sociedade através da previdência ou assistência social, os idosos vivendo à parte em lares específicos, os jovens educados pelas escolas, pela comunicação de massa, pelos companheiros e pelas tarefas necessárias à sobrevivência requerendo que ambos esposos trabalhem fora de casa.

A criança em nossa sociedade está constantemente submetida aos adultos. Sejam eles pais ou mestres, tem a tarefa de alimentá-la, vesti-la, propiciar-lhe educação ou mediar suas relações com a sociedade. A criança é socialmente dependente do adulto. Sua inferioridade física e a necessidade na qual ela se encontra de viver num mundo inteiramente concebido pelo adulto e para o mesmo, obrigam-na a se submeter a ele. A autoridade do adulto sobre a criança é uma autoridade social que estabelece um certo tipo

\begin{tabular}{lllll}
\hline Serviço Social \& Saúde & Campinas & v. 3 & n. 3 & p. 1-94 Maio 2004
\end{tabular}


de relação entre ambos. Varia de acordo com os indivíduos, alguns dos quais compensam suas frustrações sociais, afirmando seus desejos de poder absoluto sobre a criança. Difere, também, segundo as sociedades que reconhecem os diferentes tipos de adultos, direitos variáveis sobre a criança (GUERRA, 1998)

À medida que a autoridade do adulto é concebida como natural, a criança passa a submeter-se porque ele é naturalmente superior. A obediência se torna um dever exclusivo da criança e sua revolta é encarada como uma transgressão ao direito do próprio adulto. Assim a autoridade do adulto é exercida invocando o bem da criança.

Como a criança não pode ser entendida como uma entidade isolada, mas parte do núcleo familiar, o autoritarismo dispensado à criança aparece em sua face mais cruel quando este pretexto atinge a criança por meio do abuso e emprego da violência.

A violência é uma forma de relação social que está inexoravelmente atada ao modo pelo qual os homens reproduzem suas condições sociais de existência. Sob esta ótica, a violência expressa padrões de sociabilidade, modos de vida, modelos atualizados de comportamento vigentes em uma sociedade em um momento determinado do seu processo histórico. Sua compreensão não pode prescindir, por conseguinte, da referência às estruturas sociais; igualmente não pode prescindir da referência aos sujeitos que a fomentam enquanto experiência social. É no mundo da família, do cotidiano, que se instala a representação do poder doméstico, dos papéis familiares e da relação de dependência (ADORNO apud GUERRA, 1998).

Apesar da violência apresentar um forte conteúdo estrutural representado pelas relações sociais dentro de uma determinada sociedade, ela está permeada nas relações interpessoais das famílias. Os padrões, valores, e sistemas de relações sociais são vividos de forma particularizada nas famílias e são revelados tanto de forma do que preza como sagrado e fundamental para seu bem estar como pelo que teme e despreza como o pecado o crime e a violência.

Na extensa literatura sobre violência contra a criança, encontramos sua ocorrência descrita pelos autores de diversas formas. Guerra (1998) descreve quatro tipos de violência doméstica: Violência física, violência sexual, violência psicológica e negligência.

\begin{tabular}{lllll}
\hline Serviço Social \& Saúde & Campinas & v. 3 & n. 3 & p. 1-94 Maio 2004
\end{tabular} 
Vitale (1987) refere que a violência ocorre nas relações entre seres em luta configurada fisicamente, onde a força corporal é o instrumento que viola a integridade do outro em desequilíbrio entre fortes e fracos.

Capelleri et al. (1993) referem-se à violência contra a criança como abuso sexual, abuso físico e abuso emocional, considerando este último difícil de definir e mensurar.

Santos (1986) ressalta a forma velada da violência direta em oposição à violência social. Neste sentido refere-se à agressão corporal, abandono intencional temporário/ou permanente, privação de afeto, abuso sexual e até mesmo o rapto.

Marmo et al. (1999) abordam o tema do abuso físico de forma ampla, evitando a tipificação e comentam que uma criança pode ser vítima de mais de uma forma de violência. Fazem também citação de abuso físico, sexual, negligência e abuso de substâncias referindo-se ao consumo de drogas seja de maneira acidental ou intencional.

Kudse et al. (1992) também representam a violência contra a criança e o adolescente pela agressão física, abuso sexual, abandono intencional, temporário e permanente, privação alimentar e de medicamentos, falta de afeto e maus tratos psicológicos.

Faleiros (2003) cita que existem vários tipos de violência intrafamiliar, desde eliminação das pessoas até maus-tratos, ameaças, violência psicológica, violência sexual, chantagens, negligência, humilhações, designações de pessoas como doentes e incapazes.

Nos aspectos epidemiológicos vamos encontrar diferenças nas manifestações de violência contra a criança. Jason et al. (1982), colocam que ao analisarmos as diversas manifestações como uma única entidade corremos o risco de equívocos na recomendação de intervenções. Estes autores compararam 735 casos de abuso sexual e 3.486 casos de abuso físico confirmados pelo Departamento de Serviços de Proteção da Georgia, USA, encontrando diferenças em idade, sexo e relacionamento do agressor com a vítima.

Em relação ao abuso físico, Lawson; Hays (1989) mencionam que os fatores intrafamiliares tem sido focalizado nas características do abusador, do abusado e do meio ambiente. Mencionam que os pais que abusam de seus filhos se acham inúteis, tem personalidade pouco integradas e sentem conflito no íntimo. Também os pais que não se relacionam bem com outros adultos podem voltar-se a seus filhos para preencher suas necessidades emocionais. As razões para o abuso podem ocorrer quando a criança não \begin{tabular}{lllll}
\hline Serviço Social \& Saúde & Campinas & v. 3 & n. 3 & p. 1-94 Maio 2004
\end{tabular} 
corresponde a estas necessidades, e seu comportamento pode ser visto como desobediente ou de rejeição. Tais autores colocam também que a violência é socialmente aceita como método para trabalhar frustrações e estresse. Atacar os outros quando estressado é visto como parte da natureza humana. Kudse et al. (1992) em estudo realizado no CRAMI (Centro de Registros e Atenção aos Maus Tratos na Infância) de Bauru, encontraram famílias na sua maioria desestruturadas, com alto índice de alcoolismo, baixo nível sócioeconômico, com falta de responsabilidade e espírito participativo.

\section{MATERIAIS E MÉTODOS}

O ambulatório de Violência Contra a Criança e o Adolescente (VCCA) da pediatria do Hospital de Clínicas (HC) da UNICAMP atua no cuidado de crianças e adolescentes vítimas de violência há mais de dez anos, e foi reestruturado no início de 2001, com a formação de equipe interdisciplinar composta por médico, assistente social e psicólogo. Tem por objetivo atender esta população de maneira integral em suas necessidades clínicas, psicológicas e sociais, encaminhar para recursos sociais do município de origem quando necessário e orientar a família quanto a direitos e deveres previstos no Estatuto da Criança e do Adolescente (ECA).

As crianças e adolescentes atendidos neste ambulatório, são encaminhados pelo Pronto Socorro ou pelo próprio Ambulatório de Pediatria do HC, por suspeita ou confirmação de violência. São casos que necessitam de acompanhamento profissional sistematizado e continuado, onde só a denúncia não é suficiente.

Além da assistência, promove atividades de ensino, contribuindo para a formação de recursos humanos na área médica com a orientação de residentes e estagiários, assim como na formação de profissionais não-médicos com os programas de aprimoramento em serviço social e psicologia. Desenvolve projetos de pesquisa através dos quais procura estudar as variáveis significativas para o atendimento da criança vítima de violência, buscando oferecer novas perspectivas para o atendimento.

Este estudo ocorreu no ano de 2001 com o objetivo de conhecer as famílias das crianças atendidas no ambulatório em relação à constituição familiar, aspectos sócio- 
econômicos e culturais e também estabelecer o perfil das crianças vítimas de violência atendidas, assim como as circunstâncias da ocorrência e suas conseqüências.

Realizamos um estudo descritivo de 32 casos atendidos naquele ano, investigando as famílias dos pacientes, utilizando as variáveis: idade, sexo, escolaridade, procedência, renda, número de filhos, história de agressão na família e alcoolismo. Nos dados relacionados à criança as variáveis foram: idade, sexo, escolaridade, tipo de abuso sofrido, local da ocorrência da violência, informações sobre o agressor e sinais da agressão.

Os dados foram coletados dos prontuários sociais dos pacientes e digitados no programa para microcomputador EPI6, de onde obtivemos as tabelas, cruzamentos de dados e porcentagens.

\section{DISCUSSÃO DOS RESULTADOS}

As famílias das crianças estudadas pouco diferem quanto á sua formação, idade média dos pais ou grau de escolaridade quando comparadas com a população brasileira. Estas famílias no entanto, são mais empobrecidas, sofrendo maiores privações do que a média das famílias do país.

As crianças atendidas pelo grupo VCCA moram na sua maioria com ambos os pais, (61\%), sendo inferior à taxa de 75,1\% da população de São Paulo ${ }^{7}$. Encontramos $23 \%$ de crianças cuja mãe é responsável pelo domicílio, índice semelhante ao da população de São Paulo $(24,1 \%)^{8}$. Encontramos 6\% delas em lares ou famílias substitutas, o que evidencia o agravamento das conseqüências da violência.

A idade média dos pais foi de 34 anos e das mães 32 anos. A maior parte são procedentes de Campinas (53\%) e de outras cidades do estado de São Paulo ${ }^{9}$ (37\%). Duas crianças residem fora do estado de São Paulo ${ }^{10}$ (10\%).

A escolaridade dos pais das crianças vítimas de violência, 88\% com menos de 8 anos de estudo, não é significativamente inferior à da população $(82,7 \%)^{11}$. Em relação às

\footnotetext{
${ }^{7}$ Informações do censo 2000 do IBGE.

${ }^{8}$ Informações do censo 2000 do IBGE.

${ }^{9}$ As cidades do estado de São Paulo mais freqüentes foram: Hortolândia, Sumaré, Socorro, Santo Antonio da Posse, Espírito Santo do Pinhal.

${ }^{10}$ As cidades de outros estados foram: Albertina/MG e Corbélia/PR.

${ }^{11}$ Informações do censo 2000.

\begin{tabular}{lllll}
\hline Serviço Social \& Saúde & Campinas & v. 3 & n. 3 & p. 1-94 Maio 2004
\end{tabular}
} 
mães, 9,5\% são analfabetas, 76\% estudaram até o primeiro grau, 9,5\% tem o segundo grau incompleto e $5 \%$ tem o curso superior incompleto.

A informação coletada a respeito do emprego dos pais revela que o pai encontra-se ocupado no setor formal da economia em 68\% dos casos, isto é possuem vínculo empregatício formal com carteira profissional assinada ${ }^{12}$, 19\% estão no setor informal e $13 \%$ estão desempregados. As mães em grande número são donas de casa (54\%), estão empregadas formalmente $(19 \%)^{13}$, trabalham informalmente (16\%) e consideram-se desempregadas (11\%).

Em relação à renda, as famílias do VCCA recebem em média R\$ 501,00 reais enquanto que a média da população do país é de R\$ 769,00, e para o estado de São Paulo, de $\mathrm{R} \$ 1.076,00^{14}$. Heins (1984) refere em seu estudo que nos Estados Unidos, 43\% das famílias recebiam algum tipo de assistência pública, diferentemente dos $11 \%$ da população em geral.

As seqüelas da violência dentro da família aparece quando encontramos $15 \%$ de pais que foram vítimas de abuso na infância. Heins (1984) cita pesquisa realizada nos Estados Unidos com pessoas envolvidas em atos violentos e revela que elas também foram vítima de abuso quando criança, mostrando a significante contribuição que a vitimização traz não só na morbidade e mortalidade infantil, mas ao crime e violência na sociedade. Esta autora refere no mesmo estudo, que pessoas vindas de famílias violentas, com esposas espancadas, e familiares que fazem uso de álcool, podem desencadear situações caóticas na vida de seus membros que tendem a reproduzir estes modelos.

O uso do álcool foi encontrado em um terço dos pais das famílias atendidas, sendo esta substância mencionada em estudo realizado no CRAMI em 2000, que cita fatores como o álcool, a desestruturação nos relacionamento interpessoais e a dificuldade financeira como causas que contribuem para violência. O mesmo estudo cita também o uso de drogas e distúrbios psicológicos dos pais.

\footnotetext{
${ }^{12}$ As ocupações formais dos pais são na sua maioria manuais como açougueiro, servente de pedreiro, porteiro, faxineiro. As ocupações informais são jardineiro, comerciante, pedreiro, motorista.

${ }^{13}$ As ocupações formais das mães são auxiliar de escritório, florista, auxiliar de limpeza, balconista, serviços gerais. As ocupações informais são empregada doméstica, faxineira. Uma delas encontrava-se afastada em auxilio doença pelo INSS.

${ }^{14}$ Informações do censo 2000 IBGE.

\begin{tabular}{lllll}
\hline Serviço Social \& Saúde & Campinas & v. 3 & n. 3 & p. 1-94 Maio 2004
\end{tabular}
} 
Constatamos que a maioria das crianças tem idade até 10 anos (78\%), sendo que a média encontrada foi de 7 anos. Este percentual é semelhante ao das crianças vítimas de abuso sexual exclusivos ou não, com $72 \%$ delas nesta faixa etária. No caso das crianças vítima de abuso físico, o percentual desta faixa etária sobe para 83\%.

A maioria das crianças atendidas são do sexo feminino (59,3\%). Além de serem mais numerosas, as meninas são também mais jovens, sendo que 21,6\% delas tem até 5 anos de idade, enquanto entre os meninos este número é de 15,6\% (Gráfico 1). Dados semelhantes foram encontrados nos estudos de Shamroy (1980), Capelleri et al. (1993) e de Mena; Werneck (2002).

\section{Gráfico 1}

Idade e sexo da população atendida

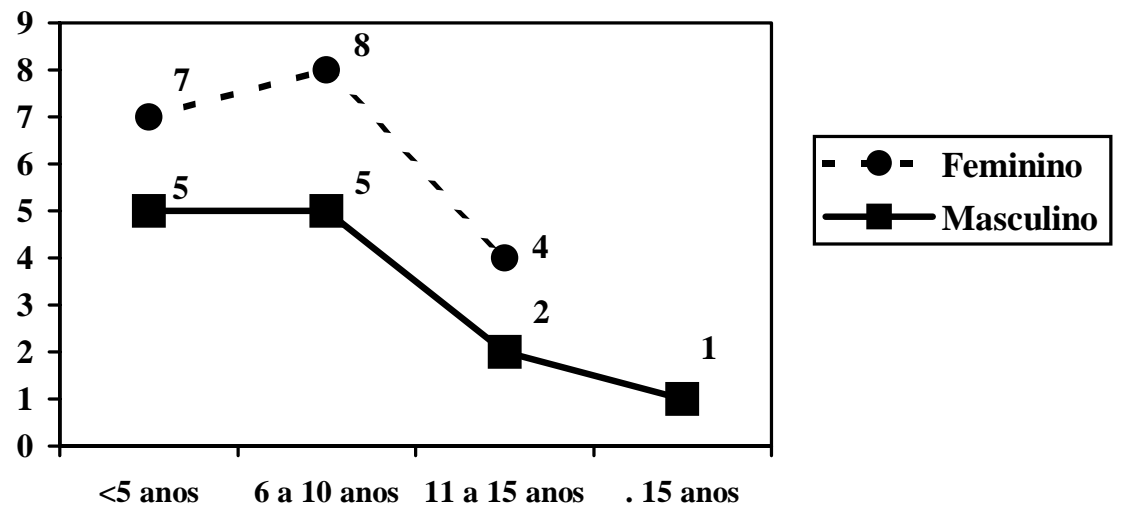

Entre as crianças atendidas pela equipe, 14 (44\%) não freqüentam a escola, três (9\%) estão na escola infantil, 12 (38\%) no primeiro grau, e três (9\%), em escola especial.

O fato de 9\% das crianças estudarem em escola especial aponta para os riscos de abuso em crianças são mais vulneráveis por serem portadoras de alguma deficiência.

$\mathrm{Na}$ área de educação sexual, as pessoas deficientes (com as mesmas emoções e desejos sexuais como cidadãos 'normais', mas possuindo muito menos informações do que eles) constituem, sem dúvida, a camada da população mais vulnerável com relação á exploração sexual e à patologia (LIPP, 1988),

\begin{tabular}{lllll}
\hline Serviço Social \& Saúde & Campinas & v. 3 & n. 3 & p. 1-94 Maio 2004
\end{tabular} 
O abuso sexual foi o tipo de violência que predominou nesta amostra com $78 \%$ dos casos confirmados, não confirmados e associados a outros tipos de abuso. Destes, 47\%, foram casos de abuso exclusivamente sexual, $16 \%$, de abuso sexual que não se confirmaram, 9\% de casos de abuso sexual associados com negligência e abuso físico e 6\% de casos considerados indefinidos ${ }^{15}$. Os dados encontrados revelaram a incidência maior de abuso sexual porque o ambulatório de VCCA não é centro de referência externa para casos de maus tratos. Os casos encaminhados para nossa equipe são referidos somente do Pronto Socorro do HC e pelos próprios profissionais da pediatria onde estas crianças são atendidas por outros problemas de saúde, e que tem dificuldade de lidar com os casos de abusos. Alguns destes casos, por tratarem-se de suspeitas às vezes, após investigação, não se caracterizam. Na literatura específica a prevalência de casos de abuso físico é mais freqüente, Capelleri et al. (1993) relatam o índice de 2.11 de casos de abuso sexual e 4,95 nos casos de abuso físico em cada 1000 crianças. O CRAMI, serviço de referência no tratamento de crianças vítimas de violência, atendeu no ano de 2000, 50\% de casos de violência física, $20 \%$ de casos de abuso sexual, $20 \%$ de casos de negligência e $10 \%$ de maus-tratos psicológicos (MARGARIDO; LIZA, 2000).

As diferenças entre o abuso sexual e o físico foram analisadas em estudo de Jason et al (1982). Estes autores não encontraram sinais visíveis de trauma em 95\% das crianças vítimas de abuso sexual que não necessitaram de hospitalização, enquanto que somente $12 \%$ das crianças vítimas de abuso físico nas mesmas condições não apresentaram sinais de lesões.

Os casos de abuso sexual são mais suscetíveis, pois mobilizam sentimentos internos das pessoas. Atingem o íntimo e o privado da moral, e o sentimento de contratransferência é mais forte. A ocorrência de mais de um tipo de abuso contra a mesma vítima evidencia o grau de sofrimento que estas crianças sofrem.

Os agressores estavam próximos das vítimas em 84\% dos casos. Pai, mãe e padrasto lideram com $37 \%$ dos casos, outros graus de parentesco aparecem em $22 \%$ e conhecidos

15 Atendemos duas crianças com diagnóstico de condiloma anal que após investigação não houve possibilidade de caracterizar como abuso sexual ou mesmo identificar o agressor.

\begin{tabular}{lllll}
\hline Serviço Social \& Saúde & Campinas & v. 3 & n. 3 & p. 1-94 Maio 2004
\end{tabular} 
das crianças foram 25\%. Somente em 6\% dos casos os agressores eram pessoas desconhecidas. Encontramos 3 casos (10\%) onde não foi possível identificar o agressor.

Entre estas pessoas haviam cinco agressores com a idade entre 11 e 13 anos. Este fato sugere que estes agressores podem, eles próprios, ser vítimas de violência necessitando de acompanhamento psicossocial, ou casos que se caracterizaram como brincadeiras entre crianças dentro de uma família que evidenciam a necessidade de orientação familiar e de limites. A agressão aconteceu na casa da crianças em 24 casos (75\%), local próximo da residência, 4 casos (12,5\%), na escola, 3 casos (10\%). Em um caso não foi possível precisar o local.

As crianças apresentaram lesões físicas, seqüelas emocionais e sinais que alteraram suas relações familiares e sociais. Com relação a lesões físicas, apresentaram dificuldade na evacuação, emagrecimento, distúrbios de sono e exposição a DSTs. As seqüelas emocionais mais freqüentes foram o medo, agressividade, agitação, dificuldades nos limites, nervosismo, choro, revolta. As seqüelas nas relações sociais apresentaram-se especialmente no retraimento da criança, dificuldade de aprendizagem e discriminação de outros colegas nos casos dos meninos. As famílias mostraram dificuldade de relacionamento, sendo que em dois casos houve necessidade de ruptura familiar, com o afastamento da criança de casa. Uma das mães precisou abandonar o marido por causa das agressões físicas sofridas pelas crianças e por ela própria. A incapacidade de proteger os filhos traduziu-se no sentimento de culpa encontrado nos pais na maioria dos casos. Esteve presente o sentimento de revolta, indignação ao deparar-se com a violência sofrida pela criança. Encontramos também casos de negação, conformismo e inclusive de mãe que culpou a criança pela sedução.

Mena e Werneck (2002) citam o medo, a culpa, a vergonha, a baixa auto-estima gerados pelo abuso que levam a criança ao isolamento. Faria (2001) relata alterações comportamentais nas crianças que mostraram-se mais agressivas e mais introvertidas. Estas crianças antes do abuso saiam mais de casa, verbalizavam mais e interagiam com os colegas com mais freqüência. 


\section{CONSIDERAÇÕES FINAIS}

O trabalho interdisciplinar junto a crianças vítima de violência e de seus familiares possibilita a leitura das interfaces clínicas, emocionais e sociais que envolvem o problema, que são interligados e estão condicionados um ao outro. A própria dureza do tipo de trabalho, a dificuldade de enfrentar um atendimento que mobiliza profundamente usuários e os profissionais cria uma interdependência entre os profissionais a ao mesmo tempo exige maior troca de saberes.

Torna-se necessário o estabelecimento de vínculo entre a equipe e familiares para propiciar um espaço onde a família possa expressar os sentimentos reprimidos sofridos pela violência. Criando um clima de confiança, a família poderá verbalizar suas ansiedades e sentimentos de culpa, reforçando a adesão ao tratamento. O atendimento à família é primordial considerando que o cuidador é a pessoa que deve proteger e pode prevenir a repetição da violência.

O fato de elevado número de crianças atendidas freqüentarem a escola, sugere a necessidade de preparo do corpo docente das escolas para identificar e orientar as crianças e familiares sobre o tema, especialmente aqueles que atuam em escolas de educação especial.

Trabalhar na proteção da criança que está em risco significa atuar em ações preventivas, que devem fazer parte das políticas de atenção à criança. Deve fazer parte também do cotidiano de todas as pessoas que, identificando, devem denunciar qualquer ato de violência. A garantia da proteção à defesa dos direitos e da cidadania estão fortalecidos pelo Conselho Tutelar, pelo Ministério Público e organizações de proteção nãogovernamentais. Somente a sensibilização por parte de todos segmentos da sociedade sobre a gravidade da questão irá incentivar o diálogo aberto que colocará fim ao silêncio que protege os que praticam atos de violência

\section{ABSTRACT}

This text deals with aspects of domestic violence from the social relationships that occur at the every day life and its historical construction. It describes the population seem at VCCA (Violence against Children and Adolescents) ambulatory in the Hospital das Clínicas da UNICAMP in aspects related to the children and its family. This article points to the importance of the ties between health professionals and the family, to the need of

\begin{tabular}{lllll}
\hline Serviço Social \& Saúde & Campinas & v. 3 & n. 3 & p. 1-94 Maio 2004
\end{tabular}


preventive actions, to the society sensibility and the free dialogue about the question based on human rights and citizenship.

KEY-WORDS: Domestic violence; Child and Adolescent; Family; Social Relationship.

\section{REFERÊNCIAS BIBLIOGRÁFICAS}

CAPPELLERI, J. C., ECKENRODE, J., POWERS, J. L. The epidemiology of child abuse: Findings from the second national incidence and prevalence study of child abuse and neglect. American Journal of Public Health, n. 83, 1622-624, 1993.

CUMINSKY, M., OJEDA, E.N.S. Crecimiento y desarrollo: salud del nino y calidad de vida del adulto. Crecimiento y Desarrollo Hechos y Tendencias. Publicacion Cientifica. n. 510, OPAS, 1988.

FALEIROS, V. P. Abuso sexual de crianças e adolescentes: Trama, drama e trauma Serviço Social \& Saúde, n. 2, p. 65-82, 2003.

FARIA, F. P. Violência Contra Criança e Adolescente - atendimento Psicológico. Depto de Pediatria FCM UNICAMP. Campinas, 2002. Mimeografado.

FREYRE, G. Casa Grande e Senzala. $2^{\circ}$ tomo, 11a edição, José Olímpio, Rio de Janeiro: 1964. 776 p.

GUERRA. V.N.A. Violência de pais contra filhos: a tragédia revisitada. $3^{\mathrm{a}}$ ed. São Paulo: Cortez, 1998. 262 p.

HEINS, M. The Battered Child Revisited. Journal of the American Medical Association. June 22/29, v. 251, n. 24, p. 3295-3300, 1984.

HELLER, A. A Concepção da família no Estado de Bem Estar Social. Serviço Social \& Sociedade. São Paulo: Cortez, n. 24, p. 5-31, 1987.

HUGO V. Les Misérables. New York: Signet Classic. 1987. 1463 p.

IBGE.Síntese de Indicadores Sociais. Censo 2000.

JASON, J., WILLIAMS, S. L., BURTON, A., ROCHAT, R. Epidemiologic differences between sexual and physical abuse. Journal of the American Medical Association. n. 247. P. 3344-3348, 1982.

KUDSEN, A. V. P.; STRINGACI, B. A. F. A. A negligência paterna e as causas conjunturais operando a desestruturação familiar e consequentemente os maus-tratos na

\begin{tabular}{lllll}
\hline Serviço Social \& Saúde & Campinas & v. 3 & n. 3 & p. 1-94 Maio 2004
\end{tabular}


infância e na adolescência. Caderno de teses do $7^{\mathbf{0}}$ Congresso Brasileiro de Assistentes Sociais. São Paulo, 1992, p. 202-04.

LAWSON, K.A.; HAYS, J.R. Self-steem and stress as factors in abuse of children. Psychological Reports, n. 65, p. 1258-1265, 1989.

LIPP, M. N. Sexo para Deficientes Mentais. São Paulo: Cortez, 1988. 93 p.

MARGARIDO, A. P.; LIZA Jr, C. Denúncia de Violência Infantil Cresce 30\%. Folha de São Paulo, São Paulo, 22 nov. 2000.

MARMO, D.B., DAVOLI, A., OGIDO, R., MARTINS FILHO, J. A violência Doméstica contra a criança. Temas de Pediatria, Campinas: Nestlé, n. 68, 1999. 32 p.

MARTOREL, R. Notes on the history of nutritional anthropometry. Federation Proceedings, n. 40, p. 2572-2576, 1981.

MENA, F.; WERNECK, G. Reféns do Segredo. Folha de São Paulo, São Paulo, 4 mar. 2002.

MINUCHIN, S. Famílias: Funcionamento e tratamento. Porto alegre: Ed. Artes Médicas, 1982. $240 \mathrm{p}$.

MULLER, R.C.L. A história familiar e a obesidade na adolescência: um estudo clínico-qualitativo com adolescentes obesos. 1999. Tese (Doutorado) Faculdade de Ciências Médicas, Universidade Estadual de Campinas. Campinas.

SANTOS, H.O. Enfoque sobre o diagnóstico e tratamento da criança maltratada. Campinas: CRAMI, 1986.

SHAMROY, J. A. A Perspective on Childhood Sexual Abuse. Social Work. San Francisco: Clearence Center , v. 25, n. 2, p. 128-31, mar. 1980.

SOIFER, R. Psicodinamismos da família com crianças: terapia familiar com técnica de jogo. Petrópolis: Vozes, 1982. 271 p.

VITALE, M.F. A violência no cotidiano das famílias de camadas populares. Serviço Social \& Sociedade. São Paulo: Cortez, n. 24, p. 32-48, ago.1987.

\begin{tabular}{lllll}
\hline Serviço Social \& Saúde & Campinas & v. 3 & n. 3 & p. 1-94 Maio 2004 \\
\hline
\end{tabular} 
